\title{
Chemical study of Dodonaea viscosa planting in Iraq
}

\author{
Sabah S. Hamadi
}

\begin{abstract}
Dodonaea viscosa Linn. is distinguished therapeutic plant where the leaves are utilized as calming, hostile to ulcer, against bacterial and antifungal operators and in the treatment of breaks. In perspective of its restorative significance and compound investigation were done, these studies gave referential data to distinguishing proof of this crude medication.

Various substance constituents have been confined from Dodonaea viscosa, however the vast majority of these were directed to the species gathered from Iraq.

Through the analysis of phenolic acids and flavonoid in Dodonaea viscosa leaves at flowering stage found 5 important compounds which is Gallic acid, Ellagic acid, Rutin as a phenolic acids and Apigenin, Kaempferol as flavonoid, the chemical analysis appear that the rutin had the highest percentage from the other compounds where reached to 279.547 .
\end{abstract}

Keywords - : Dodonaea viscosa, Chemical compound, flowering stage, medical plant.

\section{INTRODUCTION}

$D$ ODONAEA viscosa Linn. was a shrub from the Sapindaceae family (Rajamanickam et al., 2010).

The origin of Dodonaea viscosa from Australia, also it occurs throughout the tropics and subtropics and widely distributed in temperate regions of Australia, Africa, Mexico, New Zealand, India, Virgin Islands, Florida, Arizona, South America and elsewhere (West and Noble, 1984).

In Iraq it is imported from neighboring countries and cultivated in various gardens and orchards as plants Accessories and provides the appropriate shade of some vegetable crops grown underneath (AL-Yassiri, 2008).

Dodonaea viscosa have many medical properties and have been used by native peoples in all regions where it is found. It is a classic medicine worldwide, used as administered orally or as poultice to treat a great variety of diseases. Stem or leaf solution are used to treat sore larynx also the root solution used to treat colds. The stems and leaves are used to treat the fever, and seeds (in mixing with other plants and coated in honey) used to treat malaria (Rani et al., 2009), Rojas et al. (1996) also pointed to the importance of this plant medically where is used the Steam of stems were used to treat rheumatism and the leaves are used to relieve itching, fevers swellings, aches and can be used as a antispasmodic agent.

Sabah S. Hamadi__Department of Biology, College of education for pure sciences ( Ibn- Al- haitham), Baghdad University, IRAQ.
In India, the infusions of leaves were used to treat rheumatism, gout, hemorrhoids, fractures and snake bites (Kirtikar and Basu, 1995; Nadkarni and Nadkarni, 1982).

The purpose of this work is to determinate the quantitate of essential compound in Dodonaea viscosa leaves that may be useful for future studies as source of bioactive molecules.

\section{MATERIAL AND METHODS}

\section{Plants materials}

Leaves of Dodonaea viscosa were collected at flowering periods grown in the region of Baghdad at middle of Iraq. Where collected at April 2015.

\section{Extraction of phenolic acids and flavonoid}

$1.0 \mathrm{~g}$ of dry samples was crushed in small pieces in pastemortar followed by suspending fine $s=$ crushed samples into 50 $\mathrm{ml}$ of ethanol $0.1 \%$ TFA in water $(80: 20 \mathrm{~V} / \mathrm{V})$ in glass tubes. The extraction of phenolic acids and flavonoid subjected to ultrasonication (Branson sonifier, USA) at $60 \%$ duty cycles for $25 \mathrm{~min}$. at $25^{\circ} \mathrm{C}$ followed by centrifugation at $7.500 \mathrm{rpm}$ for 15 minet. The clear supernatant of each sample was subjected to charcoal treatment to remove pigments prior to evaporation under vacuum (Buchi Rotavapor Re Type), dried samples were resuspended in $1.0 \mathrm{ml} \mathrm{HPLC}$ grade methanol by vortexing, the mixture were passed through $2.5 \mu \mathrm{m}$ disposable filter and stored at $4^{\circ} \mathrm{C}$ for further analysis, then $20 \mu \mathrm{l}$ of the sample injected into HPLC system according the optimum separation condition.

Analysis of phenolic acids and flavonoid in conocarpus, the main compound was separated on FLC (Fast Liquid Chromatographic) column under the optimum condition.

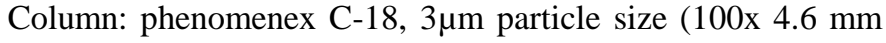
I.D.) column.

Mobile phase: linear gradient of solvent A $0.1 \%$ trifluoro acetic acid (TFA acid) in deionized water, solvent B was $0.1 \%$ TFA in gradient program from $0 \% \mathrm{~B}$ to $100 \% \mathrm{~B}$ for 12 minutes. Flow rate $1.2 \mathrm{ml} / \mathrm{min}$., the detection is $\mathrm{UV}$ at $280 \mathrm{~nm}$ and the sequences of the eluted material of the standard were as follow each standard was $25 \mu \mathrm{g} / \mathrm{ml}$.

\section{Calculation}

concentration of sample $\mu \mathrm{g} / \mathrm{l}=\frac{\text { area of sample }}{\text { areae of standard }} \times$ conc.of standard $\times$ dilution factor

The separation occurred on liquid chromatography shimadzu 10 AVLC equipped with binary delivery pump model LC-10A shimadzu, the eluted peaks were monitored by UV-Vis 10 A-SPD spectrophotometer. 


\section{Chemical analysis}

All chemical used were at least analysis grade, trifluoroacetic acid, phenolic acids standards were purchased from Sigma-Aldrich ( Steinheim, Germany).

\section{DISCUSSION}

The present chemical study affirmed that Dodonaea viscosa contains all the important compounds like phenols, alkaloids, flavonoids, saponins, tannins, sugar, steroids and gum adhesive.

Various substance constituents have been confined from Dodonaea viscosa, however the vast majority of these were directed on inside types of Iraq. The scientists have explored the concoction constituents of Dodonaea viscosa and discovered 23 flavones from seeds, bark, blooms and leaves of D.viscosa (Rani et al., 2009).

The analysis of phenolic acids and flavonoid in Dodonaea viscosa leaves at flowering stage found 5 important compounds which is Gallic acid, Ellagic acid, Rutin as a phenolic acids and Apigenin, Kaempferol as flavonoid. Critical mixes reserved from $D$. viscosa were recorded in Table 1.

Gallic acid is a trihydroxybenzoic, the chemical formula is $\mathrm{C}_{6} \mathrm{H}_{2}(\mathrm{OH})_{3} \mathrm{COOH}$ (Fig.1), a kind of phenols also consider type of natural acid, otherwise called 3,4,5-trihydroxybenzoic acid, found in gall nuts, sumac, tea leaves, oak bark, and other plants (Reynolds and Wilson, 1991). Concentration of gallic acid in this species reached to $48.672 \mu \mathrm{g} / \mathrm{ml}$.

It is used as a standard for determining the phenol content of various analysis by the Folin-Ciocalteu assay results are reported in gallic acid equivalents, gallic acid can also be used as a starting material in the synthesis of the psychedelic alkaloid mescaline (Tsao, 1951).

It is a powerless carbonic anhydrase inhibitor (Satomi et al., 1993). In fundamental exploration, gallic corrosive separated from grape seeds has been demonstrated to restrain the development of amyloid fibrils, one of the potential reasons for Alzheimer's and Parkinson's disease (Liu et al., 2013; Wang et al., 2009 and Liu et al., 2014).

One study showed that gallic corrosive has this impact on amyloid protein arrangement by altering the properties of alpha-synuclein, a protein connected with the beginning of neurodegenerative diseases (Liu et al., 2014).

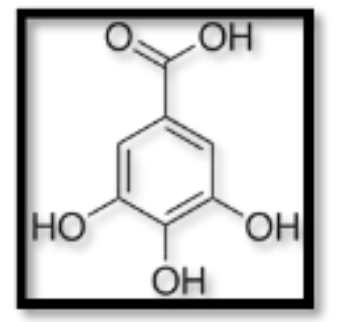

Fig 1: shape of chemical formula of Gallic acid.

Ellagic acid is a natural phenol antioxidant (Fig.2), found in numerous fruits and vegetables, the antiproliferative and antioxidant agent properties of ellagic corrosive have provoked exploration into its potential medical advantages, it has been falsely promoted as being able to anticipate and treat various human illnesses, including cancer disease, yet such claims have not been demonstrated (Food and Drug Administration, 2008). Concentration of ellagic acid in this species reached to $55.935 \mu \mathrm{g} / \mathrm{ml}$.

The highest grade of ellagic acid are found in blackberries, cranberries, pecans, pomegranates, raspberries, strawberries, walnuts, wolfberries and grapes (Vattem and Shetty, 2005). It is also found in peach and other plant foods (Loreto et al., 2011).

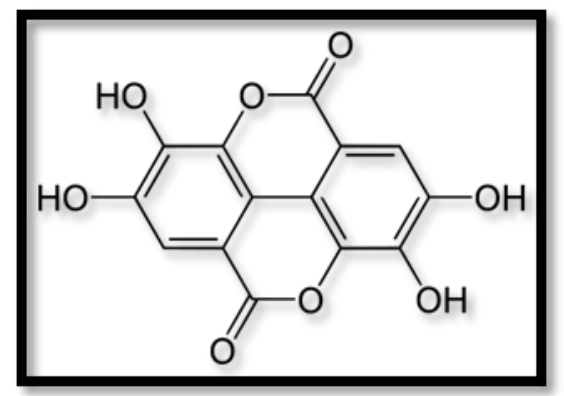

Fig. 2: shape of chemical formula of Ellagic acid.

Rutin is also one of the phenolic compounds (Fig.3), its name comes from the name of Ruta graveolens, a plant that also contains rutin, found in the invasive plant like as species D. viscosa, Carpobrotus edulis and contributes to the antibacterial (Watt and Johan, 2001) and antioxidant properties of the plant (Bouftira et al., 2012). The concentration of rutin in this species reached to 279.547 $\mu \mathrm{g} / \mathrm{ml}$.

This compound have many benefit to the human like as inhibits platelet aggregation (Navarro-Núñez et al., 2008), as well as decreases capillary permeability, making the blood thinner and improving circulation, Recent studies show rutin could help prevent blood clots, so could be used to treat patients at risk of heart attacks andstrokes (Reporter, Daily Mail, 2012), Some evidence also shows rutin can be used to treat hemorrhoids, varicosis, and microangiopathy (Chow et al., 2005).

Relatively high amount of rutin increases thyroid iodide uptake in rats and decreases serum T3 and T4 level. The decreased hormone level can be explained by its inhibitory effect produced on Thyroid peroxidase enyzme (TPO) ( Metodiewa et al., 1997) rutin is also an antioxidant compared to quercetin, acacetin, morin, hispidulin, hesperidin, and naringin, it was found to be the strongest ( Bando et al., 2010) Siddiqui (1998) survey makes reference to eighteen flavonoids including glycosides of quercetin (rutin) and isorhamnetin. Mata et al. (1991) and colleagues segregated sakuranetin from Mexican D. viscosa in 1991. 


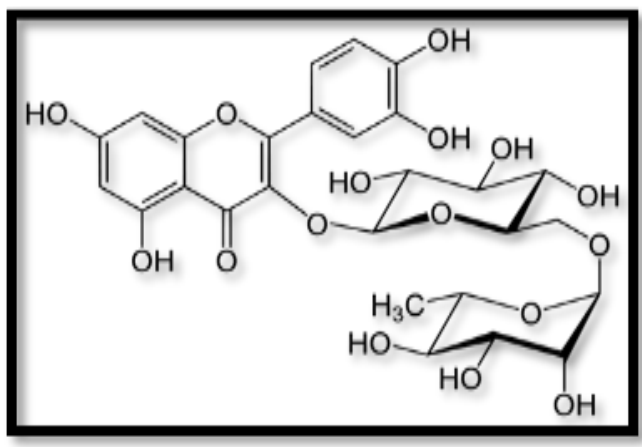

Fig 3: shape of chemical formula of Rutin

Apigenin found in many plants, is a natural product belonging to the flavone class that is the aglycone of several naturally occurring glycosides, it is a yellow crystalline solid that has been used to dye wool (Fig.4) (Mabry, 1970).

Apigenin is found in many fruits and vegetables, but parsley, celery, celeriac, and chamomile tea are the most common sources n (Taupin, 2009). Concentration of Apigenin in D. viscosa reached to $49.423 \mu \mathrm{g} / \mathrm{ml}$.

Ruela-de-Sousa et al. (2010) reported that the apigenin induces autophagy (a kind of cellular waste-recycling system) in leukemia cells, which may support a possible chemopreventive role, but that induction of autophagy simultaneously induces resistance against the chemotherapy drugvincristine.

Apigenin is a potent inhibitor of CYP2C9, an enzyme responsible for the metabolism of many pharmaceutical drugs in the body (Wang et al., 2009).

Taupin (2009) refer that the Apigenin may also stimulate adult neurogenesis, with at least one study claiming that apigenin stimulates adult neurogenesis in vivo and in vitro, by promoting neuronal differentiation and may be useful for stimulating adult neurogenesis and for the treatment of neurological diseases, disorders and injuries, by stimulating the generation of neuronal cells in the adult brain. While potentially promising, the study used rats and its effects have yet to be demonstrated in humans.

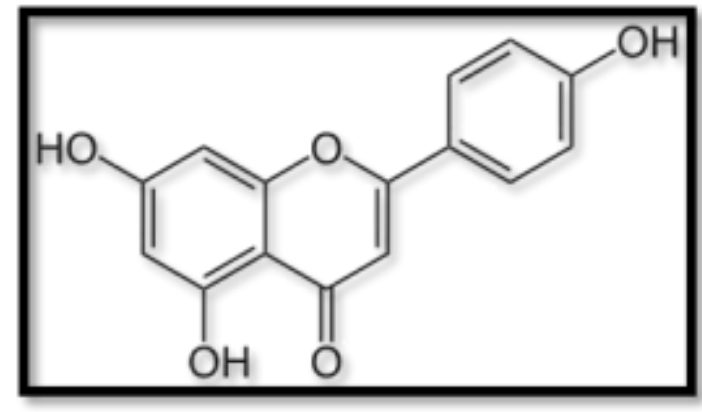

Fig 4: shape of chemical formula of Apigenin

Kaempferol is a natural flavonol, a type of flavonoid, found in a variety of plants and plant-derived foods. Kaempferol is a yellow crystalline solid with a melting point of $276-278{ }^{\circ} \mathrm{C}$ $\left(529-532^{\circ} \mathrm{F}\right)$ (Fig.5). It is slightly soluble in water and highly soluble in hot ethanol and ethers. Kaempferol acts as an antioxidant by reducing oxidative stress. Many studies suggest that consuming kaempferol may reduce the risk of various cancers and kaempferol is currently under consideration as a possible cancer treatment. (Liu, 2013).

Concentration of Kaempferol in D. viscosa reached to 11.371 $\mu \mathrm{g} / \mathrm{ml}$.

Numerous preclinical studies have shown kaempferol and some glycosides of kaempferol have a wide range of pharmacological activities, including antioxidant, antiinflammatory, antimicrobial, anticancer, cardioprotective, neuroprotective, antidiabetic, antiosteoporotic, estrogenic/antiestrogenic, anxiolytic, analgesic, and antiallergic activities (Calderon-Montaño et al., 2011) .

Ghisalberti (1998) reported that the species D. viscosa used as analgesic, anti-inflammatory, antiviral, spasmolytic, laxative, antimicrobial and hypotensive agents.

Calderon-Montaño et al. ( 2011) refer that the in vitro studies along with some animal testing has demonstrated the wide range of potential anti-cancer properties of kaempferol, it has been shown in malignant cancer cells to interrupt cell growth, limit angiogenesis, induce apoptosis and to reduce their available energy and ability to metastasize.

Kaempferol has also been shown to reduce MMP-3 protein activity inferring potential ability to reduce metastasis like as Breast cancer(Calderon-Montaño et al., 2011), Ovarian cancer (Chen et al., 2012), Leukemia (Jaganathan and Mandal, 2009) , Bladder, prostate, colorectal cancer ,Gastric cancer and Pancreatic cancer (Ute et al., 2007), Lung cancer (Kim and Choi, 2013)

As addition A correlation was found between increased levels of kaempferol in the diet and a reduced relative risk of type 2 diabetes in a cohort study in 2005 (Donnapee et al., 2014).

Cardiovascular disorders, Kaempferol has also been shown to have a protective effect on the apoptosis induced by the ischemia/reperfusion of cardiac cells. Due to this, it has a promising pharmacological role in preventing cardiovascular disease (Khalil and Sulaiman, 2010). Also use as Antibacterial activity, Anti-viral activity and Antioxidant effects (Veeresham et al., 2014).

Getie et al. (2000) disengaged generally huge amassings of quercetin, kaempferol and isorhamnetin in D.viscosa unrefined leaf remove.

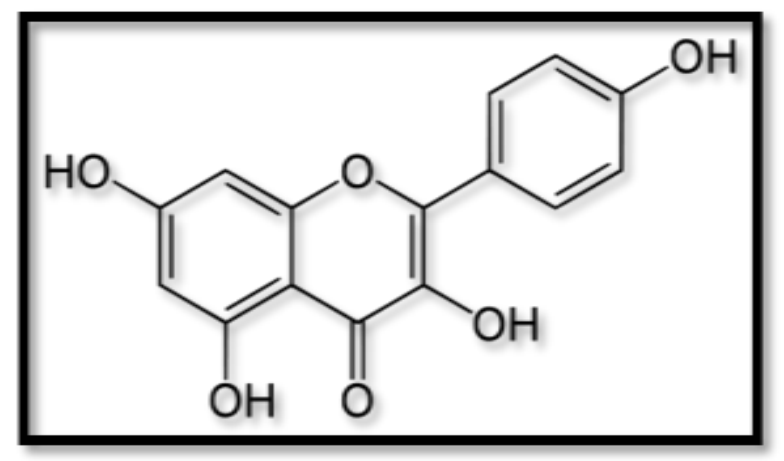

Fig 5: shape of chemical formula of Kaempferol. 


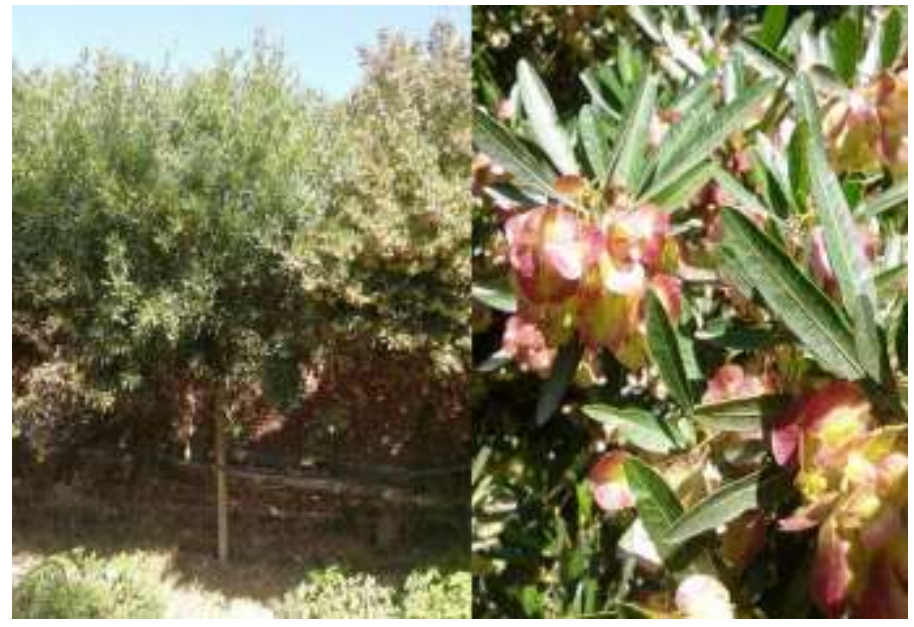

Fig1: shape of the Dodonaea viscosa tree in flowering stage.

TABLE 1

CONCENTRATION OF SOLUTION IN THE DODONAEA VISCOSA LEAVES.

\begin{tabular}{ll}
\hline solution & Concentration of the solution \\
\hline Gallic acid & 48.672 \\
Ellagic acid & 55.935
\end{tabular}

\begin{tabular}{ll} 
Rutin & 279.547 \\
\hline Apigenin & 49.423 \\
\hline Kaempferol & 11.371 \\
\hline
\end{tabular}

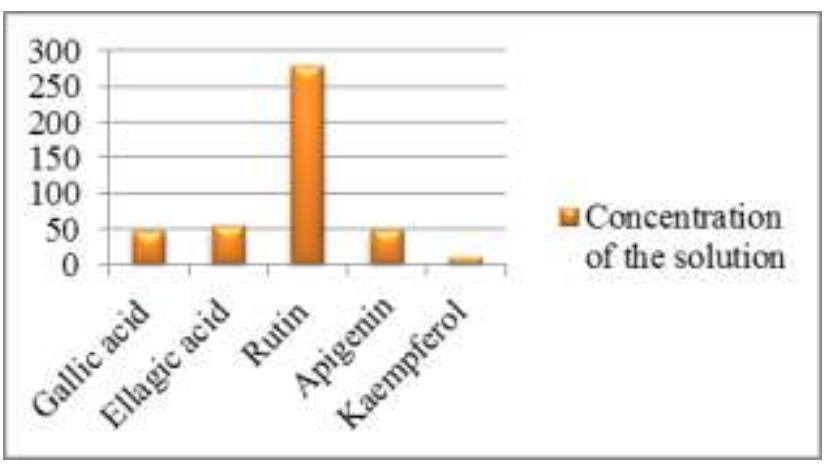

Fig 2: concentration of solution in the Dodonaea viscosa leaves.

\section{ACKNOWLEDGMENTS}

We thank to Professor D.Fadhil M. Abid, from Biotechnology Center of the Ministry of Science and Technology in Baghdad, Iraq for helping to analyses the essential oil in the plant leaves.

\section{REFERENCES}

[1] Rajamanickam, V.; Rajasekaran, A.; Anandarajagopal, K.; Sridharan, D.; Selvakumar, K. and Rathinaraj, B. S. (2010). Anti-diarrheal activity of Dodonaea viscosa root extracts. Int. J. Pharm. Bio Sci. 1(4): 182-185.

[2] West, J. G. and Noble, I. R. (1984). Analyses of digitised leaf images of the Dodonaea viscosa complex in Australia. Taxon: 595-613. https://doi.org/10.2307/1220777

[3] AL-Yassiri, A. R. (2008). Nature food and medicine. AL-Aref institution for Publications, Najaf, Iraq
[4] Rani, M. S.; Rao, S. P. and Mohan, K. (2009). Dodonaea viscosa Linn. An overview. J. Pharmaceut Res Health Care. 1: 97-112.

[5] Rojas, A. S.; Cruz, H.; Ponce, M. and Mata, R. (1996). Smooth muscle relaxing compounds from Dodonaea viscosa. Planta medica. 62:154-159

https://doi.org/10.1055/s-2006-957840

[6] Cribb, A. B. and Cribb, J. W. (1981). Wild medicine in Australia. collins, Sydney, 228.

[7] Kirtikar, K. R. and Basu, B. D. (1995). Indian Medicinal Plants, Vol. I, International Book Distributors, Dehradun, India. pp. 641-643.

[8] Nadkarni, K. M. and Nadkarni, A. K. (1982). Indian Materia Medica, Vol. I, Bombay Popular Prakashan, Bombay, India , pp. 457.

[9] Reynolds, L. D. and Wilson, N. G. (1991). Scribes and Scholars. 3rd Ed. Oxford: pp193-4

[10] Tsao, M.(1951). A New Synthesis Of Mescaline. Journal of the American Chemical Society, 73 (11): 5495-5496. ISSN 0002-7863.

[11] Satomi, H; Umemura, K; Ueno, A; Hatano, T; Okuda, T and Noro, T (1993). Carbonic anhydrase inhibitors from the pericarps of Punica granatum L. Biological \& Pharmaceutical Bulletin, 16 (8): 787-90. https://doi.org/10.1248/bpb.16.787

[12] Liu, Y; Pukala, T. L.; Musgrave, I. F.; Williams, D. M.; Dehle, F. C. and Carver, J. A. (2013). Gallic acid is the major component of grape seed extract that inhibits amyloid fibril formation. Bioorganic \& Medicinal Chemistry Letters, 23 (23): 6336-40. https://doi.org/10.1016/j.bmcl.2013.09.071

[13] Wang, Y. J.; Thomas, P; Zhong, J. H.; Bi, F. F.; Kosaraju, S; Pollard, A; Fenech, M and Zhou, X. F. (2009). Consumption of grape seed extract prevents amyloid-beta deposition and attenuates inflammation in brain of an Alzheimer's disease mouse. Neurotoxicity Research, 15 (1): 3-14. https://doi.org/10.1007/s12640-009-9000-x

[14] Liu, Y; Carver, J. A.; Calabrese, A. N. and Pukala, T. L. (2014). Gallic acid interacts with $\alpha$-synuclein to prevent the structural collapse necessary for its aggregation. Biochimica et Biophysica Acta (BBA)Proteins and Proteomics, 1844 (9): 1481-1485. https://doi.org/10.1016/j.bbapap.2014.04.013

[15] Food and Drug Administration (2008). 187 Fake Cancer 'Cures' Consumers Should Avoid, from the U.S.

[16] Vattem, D. A. and Shetty, K. (2005). Biological Function of Ellagic Acid A Review. Journal of Food Biochemistry, 29 (3): 234-266. https://doi.org/10.1111/j.1745-4514.2005.00031.x

[17] Loreto, C.; Pía, R.; Danilo, A. and Álvaro, P. (2011). Postharvest sensory and phenolic characterization of 'Elegant Lady' and 'Carson' peaches. Rodrigo Infante, Chilean Journal Of Agricultural Research, 71(3):445-451. https://doi.org/10.4067/S0718-58392011000300016

[18] Watt, A. and Johan, C. (2001). Purification and identification of active antibacterial components in Carpobrotusedulis L. Elmarie van der, Pretorius, Journal of Ethnopharmacology, 76, (1): 87-91. https://doi.org/10.1016/S0378-8741(01)00197-0

[19] Bouftira, I.; Chedly, A. and Souad, S. (2012). Antioxidant and Antibacterial Properties of Mesembryanthemum crystallinum and Carpobrotus edulis Extracts. Advances in Chemical Engineering and Science, 2 (3): 359-365. https://doi.org/10.4236/aces.2012.23042

[20] Navarro-Núñez, L.; Lozano, M. L.; Palomo, M.; Martínez, C.; Vicente, V.; Castillo, J.; Benavente-García, O.; Diaz-Ricart, M.; Escolar, G. and Rivera, J. (2008). Apigenin Inhibits Platelet Adhesion and Thrombus Formation and Synergizes with Aspirin in the Suppression of the Arachidonic Acid Pathway. J. Agric. Food Chem. 56 (9): 2970-6. https://doi.org/10.1021/jf0723209

[21] Reporter, Daily Mail (9 May 2012). "Chemical found in apples, onions and green tea can help beat blood clots". London: Mail Online. Retrieved 11 May 2012.

[22] Chow, J.; Shen, S.; Huan, S. K.; Lin, H. and Chen, Y. (2005). Quercetin, but not rutin and quercitrin, prevention of $\mathrm{H} 2 \mathrm{O} 2$-induced apoptosis via anti-oxidant activity and heme oxygenase gene expression in macrophages. Biochemical Pharmacology 69 (12): 183951.

https://doi.org/10.1016/j.bcp.2005.03.017

[23] Metodiewa, D.; Kochman, A. and Karolczak, S. (1997). Evidence for antiradical and antioxidant properties of four biologically active N,N- 
Diethylaminoethyl ethers of flavaone oximes: A comparison with natural polyphenolic flavonoid rutin action. IUBMB Life 41 (5): 10671080. https://doi.org/10.1080/1521654970020214

[24] Bando, N.; Muraki, N.; Murota, K.; Terao, J. and Yamanishi, R. (2010). Ingested quercetin but not rutin increases accumulation of hepatic $\beta$-carotene in BALB/c mice. Molecular Nutrition \& Food Research 54: S261. https://doi.org/10.1002/mnfr.200900329

[25] Siddiqui, A. A. (1998). Chemical and pharmacological evaluation of Dodonaea viscosa. Asian Journal of Chemistry , 10:14-16.

[26] Mata, R.; Contreras, J. L.; Crisanto, D.; Pereda-Miranda, R.; Castaneda, P. and Del-Rio, F. (1991). Chemical studies on Mexican plants used in traditional medicine, XVIII. New secondary metabolites from Dodonaea viscosa. Journal of natural products 54(3): 913-917. https://doi.org/10.1021/np50075a033

[27] Mabry, E. (1970). The Systematic Identification of Flavonoids. page 81. https://doi.org/10.1007/978-3-642-88458-0

[28] Taupin, P (2009). Apigenin and related compounds stimulate adult neurogenesis. Mars, Inc., the Salk Institute for Biological Studies: WO2008147483. Expert opinion on therapeutic patents 19 (4): 523-7.

[29] Ruela-de-Sousa, R. R.; Fuhler, G. M.; Blom, N.; Ferreira, C. V.; Aoyama, H. and Peppelenbosch, M. P. (2010). Cytotoxicity of apigenin on leukemia cell lines: implications for prevention and therapy. Cell Death and Disease 1 (e19): 1-11 https://doi.org/10.1038/cddis.2009.18

[30] Wang, S. D.; Zhou, Y.; Guo, Y. H.; Wang, Y.; Zhou, J.; Li, H. and Fawcett, J. P. (2009). Mechanism of CYP2C9 inhibition by flavones and flavonols. Drug Metabolism and Disposition 37 (3): 629-634. https://doi.org/10.1124/dmd.108.023416

[31] Taupin, P. (2009). Apigenin and related compounds stimulate adult neurogenesis. Mars, Inc., the Salk Institute for Biological Studies: WO2008147483. Expert opinion on therapeutic patents 19 (4): 523-7.

[32] Liu, R. H. (2013). Health-promoting components of fruits and vegetables in the diet. Adv Nutr. 4 (3): 384S-92S. https://doi.org/10.3945/an.112.003517

[33] Calderon-Montaño, J. M.; Burgos-Moron, E.; Perez-Guerrero, C. and Lopez-Lazaro, M. (2011). A review on the dietary flavonoid kaempferol. Mini Rev Med Chem. 11 (4): 298-344. https://doi.org/10.2174/138955711795305335

[34] Ghisalberti, E. L. (1998). Ethnopharmacology and phytochemistry of Dodonaea species Fitotherapia. LXIX. 99-113.

[35] Chen, S. S.; Michael, A. and Butler-Manuel, S. A. (2012). Advances in the Treatment of Ovarian Cancer: A Potential Role of Antiinflammatory Phytochemicals. Discov Med. 13 (68):7-17.

[36] Jaganathan, S. K. and Mandal, M. (2009). Antiproliferative Effects of Honey and of its Polyphenols: A Review. J Biomed Biotechnol. 830616. https://doi.org/10.1155/2009/830616

[37] Ute, N.; Suzanne, M.; Wilkens, P.; Lynne, R.; Brian, H. and Kolone N. (2007). Flavonols and Pancreatic Cancer Risk. American Journal of Epidemiology 166 (8): 924-931. https://doi.org/10.1093/aje/kwm172

[38] Kim, S. H. and Choi, K. C. (2013). Anti-cancer Effect and Underlying Mechanism(s) of Kaempferol, a Phytoestrogen, on the Regulation of Apoptosis in Diverse Cancer Cell Models. Toxicol Res. 29 (4): 229 234 https://doi.org/10.5487/TR.2013.29.4.229

[39] Donnapee, S.; Li, J.; Yang, X.; Ge, A. H.; Donkor, P. O.; Gao, X. M. and Chang, Y. X. (2014). Cuscuta chinensis lam.: A systematic review on Ethnopharmacology, phytochemistry and pharmacology of an important traditional herbal medicine. J Ethnopharmacol. 157 (C): 292-308. https://doi.org/10.1016/j.jep.2014.09.032

[40] Khalil, M. I. and Sulaiman, S. A. (2010). The Potential Role of Honey and its Polyphenols in Preventing Heart Diseases: A Review. Afr J Tradit Complement Altern Med. 7 (4): 315-21. https://doi.org/10.4314/ajtcam.v7i4.56693

[41] Veeresham, C.; Rama-Rao, A. and Asres, K. (2014). Aldose Reductase Inhibitors of Plant Origin. Phytother Res. 28 (3): 317-33. https://doi.org/10.1002/ptr.5000
[42] Getie, M. G.; Rietz, R. and Neubert, R. H. H. (2000). Distribution of quercetin, kaempferol andisorhamnetin in some Ethiopian medicinal plants used for the treatment of dermatologicaldisorders. Ethiopian Pharmacy Journal, 18: 25-34. 